\title{
Simultaneous detection of Human Immunodeficiency Virus 1 and Hepatitis B virus infections using a dual-label time-resolved fluorometric assay
}

Tiina Myyryläinen ${ }^{1 \dagger}$, Sheikh M Talha ${ }^{2 \dagger}$, Sathyamangalam Swaminathan ${ }^{2}$, Raija Vainionpää ${ }^{3}$, Tero Soukka ${ }^{1}$, Navin Khanna ${ }^{2}$, Kim Pettersson ${ }^{1 *}$

\begin{abstract}
A highly specific and novel dual-label time-resolved immunofluorometric assay was developed exploiting the unique emission wavelengths of the intrinsically fluorescent terbium $\left(\mathrm{Tb}^{3+}\right)$ and europium $\left(\mathrm{Eu}^{3+}\right)$ tracers for the simultaneous detection of human immunodeficiency virus 1 (HIV-1) and hepatitis B virus (HBV) infections, respectively. HIV-1 infection was detected using a double antigen sandwich format wherein anti-HIV-1 antibodies were captured using an in vivo biotinylated version of a chimeric HIV-1 antigen and revealed using the same antigen labeled with $\mathrm{Tb}^{3+}$ chelate. Hepatitis B surface antigen ( $\mathrm{HBsAg}$ ), which served as the marker of HBV infection, was detected in a double antibody sandwich using two monoclonal antibodies (mAbs), one chemically biotinylated to capture, and the other labeled with $\mathrm{Eu}^{3+}$ nanoparticles, to reveal. The performance of the assay was evaluated using a collection $(n=60)$ of in-house and commercially available human sera panels. This evaluation showed the dual-label assay to possess high degrees of specificity and sensitivity, comparable to those of commercially available, single analyte-specific kits for the detection of HBsAg antigen and anti-HIV antibodies. This work demonstrates the feasibility of developing a potentially time- and resource-saving multiplex assay for screening serum samples for multiple infections in a blood bank setting.
\end{abstract}

\section{Findings}

The World Health Organization recommends screening for infections by human immunodeficiency virus (HIV), hepatitis $\mathrm{B}$ virus (HBV), hepatitis $\mathrm{C}$ virus (HCV) and Treponema pallidum (syphilis) for the provision of a safe blood supply [1]. Currently these infections are detected using independent tests. In a step towards a multiplex assay for blood bank screening, we have explored the feasibility of developing an integrated duallabel assay designed to identify infections by HIV and HBV.

We have exploited the inherent fluorescence of lanthanide chelates to develop a screening assay for the simultaneous detection of HIV and HBV infections

\footnotetext{
* Correspondence: kim.pettersson@utu.fi

† Contributed equally

${ }^{1}$ Department of Biotechnology, University of Turku, Turku, Finland

Full list of author information is available at the end of the article
}

based on time resolved fluorometry (TRF) of terbium $\left(\mathrm{Tb}^{3+}\right)$ and europium $\left(\mathrm{Eu}^{3+}\right)$ labels. TRF technology using lanthanide chelates with high fluorescence intensity coupled to very low background signals, made possible by the temporal separation of long-lived emission signals, has the potential for achieving very high levels of sensitivity [2-5]. Consequently, lanthanide chelatebased TRF assays are available commercially for the detection of hormones, tumor markers, celiac disease markers and for neonatal screening. A recombinant HIV-1 env ( $r$-HIV-1env) antigen and two HBsAg specific monoclonal antibodies (mAbs), $21 \mathrm{~B}$ and $5 \mathrm{~S}$, were created first (unpublished data). The principle of the dual-label TRF assay is depicted pictorially in Figure 1A. Serum analytes were captured efficiently using specific biotinylated binders immobilized at high density on streptavidin (SA)-coated plates. We used an in vivo biotinylated version of the $r$-HIV-1 env protein ( $r$-Bio- 


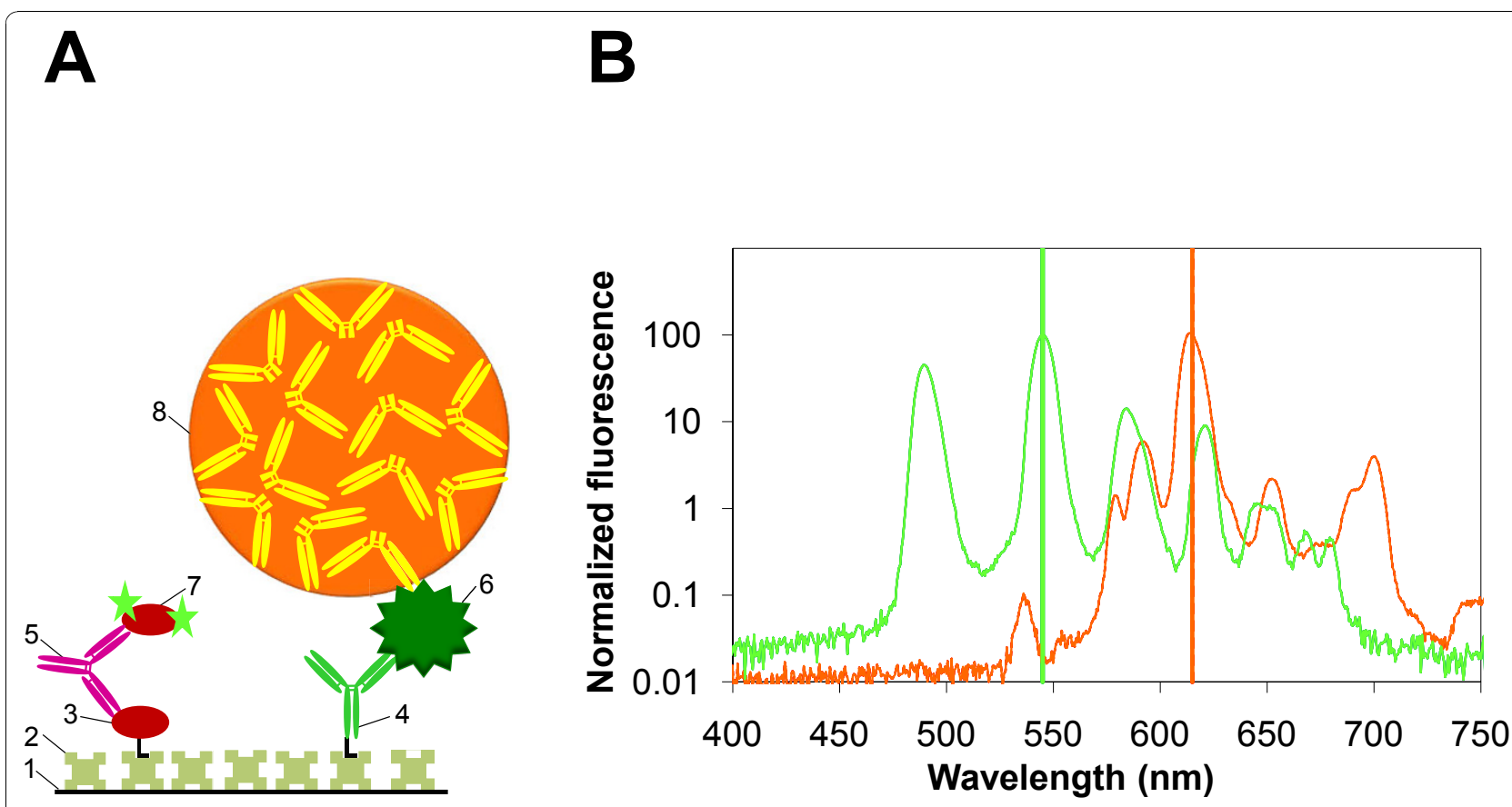

Figure 1 Design of the dual-label time-resolved immunofluorometric assay. (A) A schematic illustration of the assay for simultaneous detection of HIV and HBV infections. The Arabic numerals indicate individual assay components: (1) microtitre well surface; (2) streptavidin; (3) rBio-HIV-1 Env; (4) Bio mAb 21B; (5) anti-HIV-1 antibodies in infected serum; (6) HBsAg in infected serum; (7) r-HIV-1env labeled with Tb ${ }^{3+}$ chelate (which is measured at $545 \mathrm{~nm}$ ); (8) $5 \mathrm{~S} \mathrm{~F}(\mathrm{ab})_{2}$ coated $\mathrm{Eu}^{3+}$ nanoparticles (which is measured at $615 \mathrm{~nm}$ ). (B) The emission spectra of Tb ${ }^{3+}$ chelate $^{3}$ (green line) and $\mathrm{Eu}^{3+}$ nanoparticles (orange line).

HIV-1 env) and chemically biotinylated mAb 21B (BiomAb 21B), immobilized on SA-coated microtiter wells, to capture anti-HIV-1 antibodies and HBsAg, respectively. Captured anti-HIV-1 antibodies were detected with $\mathrm{Tb}^{3+}$ chelate-labeled $\mathrm{r}-\mathrm{HIV}-1 \mathrm{env}$ antigen. For the detection of captured HBsAg, we utilized the $\mathrm{F}(\mathrm{ab})_{2}$ fragment of $5 \mathrm{~S}$ mAb. The Fc portion of the antibody molecule can frequently give rise to falsely positive or negative results through interaction with other reagents of the test or normal constituents of patient samples. Its elimination enzymatically or through recombinant expression of antibody fragment has been shown to significantly decrease this source of error [6,7]. Therefore, we cleaved $5 \mathrm{~S}$ mAb with bromelain to produce $5 \mathrm{~S} \mathrm{~F}$ $(\mathrm{ab})_{2}$ fragment, and covalently coupled it to carboxylactivated Fluoro-Max ${ }^{\text {Tx }}$ polystyrene nanoparticles, doped with $\mathrm{Eu}^{3+}$ chelate and used it as the tracer to detect HBsAg. In contrast to $\mathrm{Tb}^{3+}, \mathrm{Eu}^{3+}$ is available commercially in a nanoparticle format, which has been shown to improve the detection sensitivity greatly [8-10]. The TRF assay described here differs from those reported earlier. It utilizes labels that provide optimal fluorescence without the need for a separate dissociation-based fluorescence enhancement of the DELFIA assays $[2,4,5]$ or a non-dissociative signal development step of the LANFIA procedure [3] and permits measurement of the fluorescence directly from the dry surface of the microtiter wells.

We first evaluated the potential for cross-talk between the two fluorescent labels. The emission spectra of $\mathrm{Eu}^{3+}$ chelate-doped nanoparticles and $\mathrm{Tb}^{3+}$ chelate, recorded using a Cary Eclipse spectrofluorometer (Varian, USA) are shown in Figure 1B. The data show that while $\mathrm{Eu}^{3+}$ fluorescence at the emission maximum of $\mathrm{Tb}^{3+}$ is negligible $(<0.02 \%$ at $545 \mathrm{~nm}), \mathrm{Tb}^{3+}$ fluorescence at $615 \mathrm{~nm}$, the emission maximum of the $\mathrm{Eu}^{3+}$, was almost $3 \%$. In order to determine the magnitude of this cross-talk in the actual assay setting, a dilution series of $\mathrm{Tb}^{3+}$ labeled r-Bio-HIV-1env was immobilized on to SA-coated microtiter wells, followed by washing and measurement of fluorescence, using a Victor 1420 multilabel counter (Perkin Elmer Life and Analytical Sciences, Singapore), at $545 \mathrm{~nm}$ and $615 \mathrm{~nm}$. The results of this experiment, shown in Figure 2A, indicate the magnitude of $\mathrm{Tb}^{3+}$ cross-talk one may expect while measuring $\mathrm{Eu}^{3+}$ fluorescence at $615 \mathrm{~nm}$ in a dual-label assay. Depending on the instrument used, $\mathrm{Tb}^{3+}$ cross-talk was determined to range from $1.2-2.5 \%$. Thus, all $\mathrm{Eu}^{3+}$ fluorescence data were corrected using the measuring instrument-specific $\mathrm{Tb}^{3+}$ cross-talk. $\mathrm{Eu}^{3+}$ cross-talk in $\mathrm{Tb}^{3+}$ fluorescence 


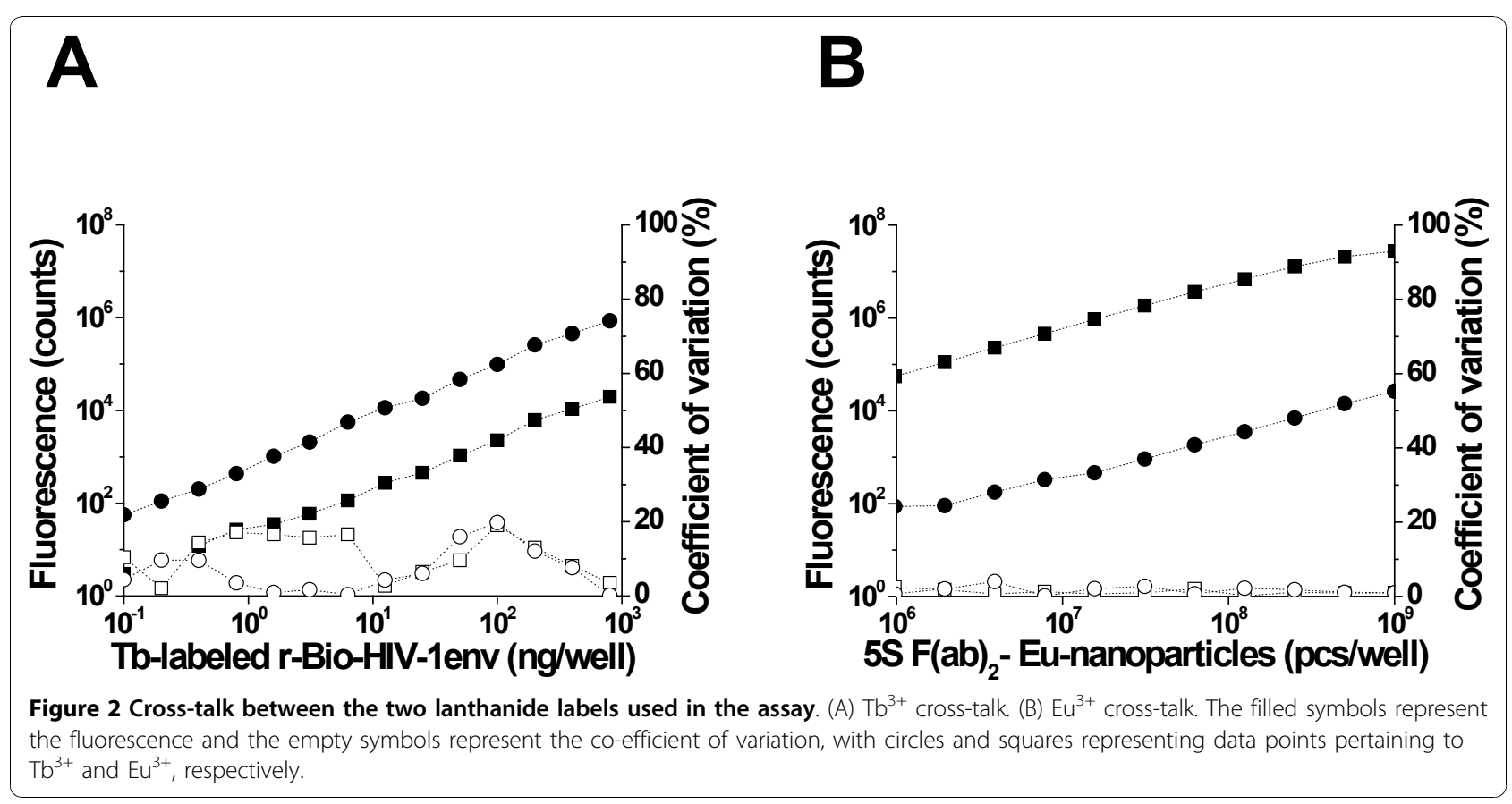

measurement was determined as shown in Figure 2B. In this experiment, chemically biotinylated rHBsAg was immobilized on SA-coated microtiter wells, and incubated with a dilution series of $\mathrm{Eu}^{3+}$ doped $5 \mathrm{~S} \mathrm{~F}(\mathrm{ab})_{2}$ nanoparticles. As before, fluorescence was measured at both wavelengths $(545 \mathrm{~nm}$ and $615 \mathrm{~nm})$. The results showed that $\mathrm{Eu}^{3+}$ is unlikely to manifest significant cross-talk during the measurement of $\mathrm{Tb}^{3+}$ fluorescence at $545 \mathrm{~nm}$.

Prior to deploying the dual-label assay for the simultaneous detection of both HIV-1 and HBV infections, we evaluated its sensitivity to detect each of the two analytes (anti-HIV-1 antibody and HBsAg) in the absence (single-label) and presence (dual-label) of the binders of the other analyte. Using rHBsAg (subtype $a d w$ ), ranging from $0.02-200 \mathrm{ng} / \mathrm{mL}$, the dual-label assay was performed in the absence and presence of the anti-HIV-1 antibody binders, $\mathrm{r}$-Bio-HIV-1 env and $\mathrm{Tb}^{3+}$ chelate labeled $\mathrm{r}$-HIV-1 env. Unlike in the case of rHBsAg, it is not possible to use 'known' concentrations of anti-HIV1 antibodies, given their polyclonal nature and inherent differences in affinity and specificity for HIV-1 antigens. Thus, to explore the sensitivity of detection of anti-HIV1 antibodies, the dual-label assay was performed using serial dilutions (as a surrogate for a range of known concentrations) of an anti-HIV-1 antibody-containing serum sample in the absence and presence of the HBsAg binders, Bio-mAb $21 \mathrm{~B}$ and $5 \mathrm{~S} \mathrm{~F}(\mathrm{ab})_{2}$ coated $\mathrm{Eu}^{3+}$ nanoparticles. The data shown in Figure 3 reveal that there was very good correlation between the single and dual-label formats of the assay with respect to each of the two analytes tested. There was essentially no discernible difference in the lowest limits of detection (LLOD) of either analyte when the two assay formats were compared. For HBsAg, the LLOD was 0.011 and $0.013 \mathrm{ng} / \mathrm{mL}$, respectively, in the absence and presence of anti-HIV-1 antibody binders. The corresponding LLOD for anti-HIV-1 antibody detection cannot be designated for the reason mentioned above. Nevertheless, it is evident from Figure $3 \mathrm{~B}$ that antibodies present in as low as 0.01 to $0.001 \mu \mathrm{l}$ of the HIV-1 positive serum (used in this experiment) are detected in this assay, which reaches saturation at $1 \mu \mathrm{l}$ of this serum. Overall, the data justify the conclusion that combining the anti-HIV-1 antibody- and HBsAg-binders in a duallabel assay will not compromise the sensitivity of detection of either analyte. This is further borne out by the analysis of sera that contain HBsAg as well as anti-HIV1 antibodies (see below).

Next, we tested the feasibility of the dual-label assay for detecting HIV and HBV infections in human serum samples. First, we used an in-house panel of 100 'normal' serum samples that were confirmed to be negative for both $\mathrm{HIV}$ and $\mathrm{HBV}$ infections $\left(\mathrm{HIV}^{-} / \mathrm{HBV}^{-}\right)$, using Vidas HIV Duo Quick and HBsAg Ultra kits (bioMérieux SA, Marcy I'Etoile, France). The mean $\mathrm{Tb}^{3+}$ and $\mathrm{Eu}^{3+}$ fluorescence readouts of these normal serum samples plus $5 \times$ standard deviation (SD) of the corresponding means were used as the cut-offs for anti-HIV antibodies and HBsAg determinations, respectively. Next, we tested a set of 37 serum samples (Department of Virology, University of Turku). These represented 


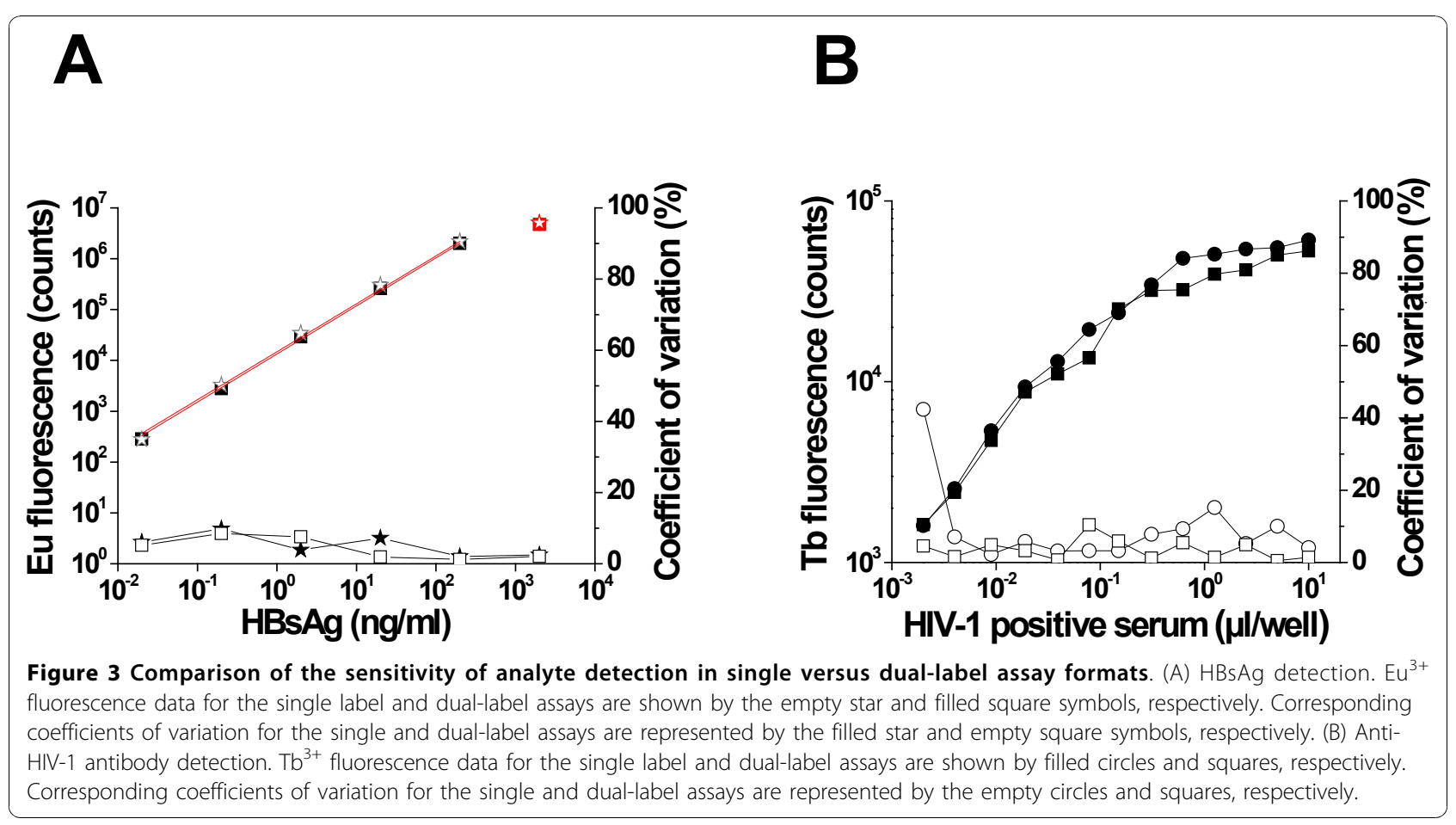

infected samples of which 25 were $\mathrm{HBV}^{+}$and $12 \mathrm{HIV}^{+}$, using the Vidas commercial assays mentioned above. For a given analyte, signal/cut-off $(\mathrm{S} / \mathrm{Co})$ ratios $<1$ and $\geq 1$ were considered as negative and positive, respectively. The results are summarized in Table 1 . An analysis of these serum samples using the dual-label assay showed that while all $12 \mathrm{HIV}^{+}$serum samples were identified to contain anti-HIV-1 antibodies, HBsAg

Table 1 Evaluation of the dual-label TRF assay for simultaneous detection of HIV-1 and HBV infections

\begin{tabular}{|c|c|c|c|}
\hline Grp & $n$ & $\begin{array}{l}\text { Infection profile } \\
\text { (Ref assay) }^{a}\end{array}$ & $\begin{array}{l}\text { Dual-label assay } \\
\left(\mathrm{HIV}^{+} 1^{+} / \mathrm{HBV}^{+}\right)^{\mathrm{b}}\end{array}$ \\
\hline \multicolumn{4}{|c|}{ In-house sera panel } \\
\hline 1 & 25 & $\mathrm{HIV}-1^{-} / \mathrm{HBV}^{+}$ & $0 / 23^{c}$ \\
\hline 2 & 12 & $\mathrm{HIV}-1^{+} / \mathrm{HBV}$ & $12 / 0$ \\
\hline \multicolumn{4}{|c|}{ BBI co-infection panel } \\
\hline 3 & 13 & $\mathrm{HIV}-1^{+} / \mathrm{HBV}^{+}$ & $13 / 10^{d}$ \\
\hline 4 & 6 & $\mathrm{HIV}-1^{-} / \mathrm{HBV}^{+}$ & $0 / 6$ \\
\hline 5 & 3 & $\mathrm{HIV}-1^{+} / \mathrm{HBV}$ & $3 / 0$ \\
\hline 6 & 1 & HIV-1/HBV & $0 / 0$ \\
\hline
\end{tabular}

a The Reference assays for the in-house sera panel were Vidas HIV Duo Quick and HBsAg Ultra assays, for anti-HIV-1 antibody and HBsAg detection, respectively; the Reference assays for the BBI co-infection panel are mentioned in the Supplementary Information (see Additional file 1). The " + " and "-" superscripts indicate positive and negative tests, respectively.

b This column indicates the results obtained using the dual-label assay described in the text. The numbers shown indicate the serum samples that scored positive for both analytes in the dual-label assay.

'missed two $\mathrm{HBsAg}^{+}$serum samples

${ }^{d}$ missed three $\mathrm{HBsAg}^{+}$serum samples antigen could be detected in 23 of the $25 \mathrm{HBV}^{+}$serum samples. Of the two remaining $\mathrm{HBV}^{+}$serum samples, one was a borderline sample (see Additional file 1: Figure S1). These two serum samples tested negative for HBsAg using the single label assay also (data not shown), suggesting that the dual-label assay format per se did not compromise sensitivity of HBsAg detection.

To examine the performance of the dual-label assay in the background of other infections, we tested it against a BBI viral co-infection panel PCA 201 (from Boston Biomedica Inc., now SeraCare Life Sciences Inc., Milford MA). This panel was characterized for HIV-1, HBV, HCV and HTLV infections using standard commercially available reference tests (see Additional file 1: Table S1). Twenty-three of the 25 panel members were available for this study. One member of this panel was seronegative for both HIV-1 and HBV infections (sample\# 24). The dual-label assay identified this correctly as $\mathrm{HIV}^{-} /$ $\mathrm{HBV}^{-}$. Of the remaining 22 serum samples, 16 and 19 samples were designated as $\mathrm{HIV}^{+}$and $\mathrm{HBV}^{+}$, respectively, with 13 samples seropositive for both HIV-1 and $\mathrm{HBV}$ (Table 1). Out of these $13 \mathrm{HIV}^{+} / \mathrm{HBV}^{+}$serum samples, 6 were positive for HCV, and two for HTLV as well. The remaining three $\mathrm{HIV}^{+}$serum samples were negative for HBV but positive for HCV and HTLV. The dual-label assay could identify 16 out of $16 \mathrm{HIV}^{+}$serum samples $(100 \%)$. It is noteworthy that one borderline serum sample (sample\# 20, S/Co ratio $=1.1$ ) was also picked up unambiguously by the dual-label test (S/Co ratio $=14.8)$. This essentially is indicative of enhanced 
sensitivity of the dual-label test and is in agreement with the conclusions based on Figure 3B. Our data show that the dual-label assay is capable of identifying $\mathrm{HIV}^{+}$ serum samples regardless of the presence or absence of HBV, HCV and HTLV co-infections, with high sensitivity and specificity. However, it is to be noted that we have used r-HIV-1env as the antigen to detect antiHIV-1 antibodies to obtain a technical proof-of-concept. Of the $19 \mathrm{HBV}^{+}$serum samples, 13 samples were also $\mathrm{HIV}^{+}$, as mentioned already, and the rest $(\mathrm{n}=6)$ were $\mathrm{HIV}^{-}$. Many of these serum samples were co-infected with HCV, HTLV or both. The dual-label assay identified 16 of the $19 \mathrm{HBV}^{+}$serum samples, regardless of $\mathrm{HIV}, \mathrm{HCV}$ or HTLV infection status. Of the $3 \mathrm{HBV}^{+}$ serum samples that were missed by the dual-label assay, one was a borderline sample (sample\# 9, S/Co ratio = $1)$. As with the in-house serum samples, these $3 \mathrm{mem}$ bers of panel PCA 201 also turned out to be false-negative in the single label HBV assay. This rules out the possibility that $\mathrm{Tb}^{3+}$ cross-talk may have masked $\mathrm{Eu}^{3+}$ signals and interfered with HBsAg detection. The data show that the concordance of the dual-label assay with regard to HBsAg detection using the reference assay (Abbott EIA) is $84 \%$. This presumably stems from low sensitivity of the mAbs used for detection of HBsAg, despite the use of a tracer $\mathrm{F}(\mathrm{ab})_{2}-\mathrm{Eu}^{3+}$ nanoparticle for the detection of this analyte in the dual-label assay.

In conclusion, we have developed a lanthanide fluorescent reporter-based dual-label assay for the simultaneous detection of HIV-1 and HBV infections in donated blood samples. The high sensitivity of this approach derives from the temporal resolution of the long lifetime high intensity fluorescence of $\mathrm{Eu}^{3+}$ and $\mathrm{Tb}^{3+}$ lanthanide tracers measured by TRF. Qdots have emerged recently as highly efficient fluorescent probes. However, these have short-lived fluorescence. Therefore, TRF cannot be employed to measure their signals and their detection is limited by autofluorecence. Further, the $\mathrm{Eu}^{3+}$ and $\mathrm{Tb}^{3+}$ tracers used in this study are inherently fluorescent, obviating the need for additional signal development steps as in the DELFIA and LANFIA methods [2-5], and can be measured directly from the dry surface of the microtiter wells. The simultaneous detection of two analytes combined with a relatively simpler assay format eliminating the extra signal development step, will contribute to both cost and time saving.

To our knowledge, this work, which represents the first report of a dual-label HIV/HBV assay, demonstrates in principle, the feasibility of developing a multiplex assay for screening samples for multiple infections in a blood bank setting. However, a limitation is the potential for interference among the reporters, as illustrated by the $\mathrm{Tb}^{3+}$ cross-talk in $\mathrm{Eu}^{3+}$ measurements in this study. It may be a challenging task to eliminate the interference arising out of cross-talk among multiple fluorescent reporters. One way of circumventing the cross-talk problem in multiplexing would be to design an array-in well strategy in which multiple analyte-capturing reagents are spatially isolated in the same well and used in conjunction with a single reporter, for example $\mathrm{Eu}^{3+}$ nanoparticles. In this set up, analytes can be identified based on the specific locations from which signals are detected.

\section{Additional material}

Additional file 1: Myyrylainen et al (Addl files). The file is organized into three sections. Section 1 describes essential Methods. Section 2 provides S/Co data on the evaluation of in-house sera panel using the dual-label TRF assay (Figure S1). Section 3 provides S/Co data on the evaluation of the BBI viral co-infection panel PCA 201 using the duallabel TRF assay (Table S1)

\section{Acknowledgements}

This work was supported by grants from the Department of Biotechnology, Government of India and Academy of Finland (grant \#115524) under a joint Indo-Finnish collaborative research programme. SMT was the recipient of a research fellowship from the University Grants Commission, Government of India.

\section{Author details}

${ }^{1}$ Department of Biotechnology, University of Turku, Turku, Finland.

${ }^{2}$ Recombinant Gene Products Group, International Centre for Genetic Engineering \& Biotechnology, Aruna Asaf Ali Marg, New Delhi-110067, India. ${ }^{3}$ Department of Virology, University of Turku, Turku, Finland.

\section{Authors' contributions}

TM and SMT performed experiments. RV collected and characterized the human sera samples. SS and NK designed the HIV antigen and generated the monoclonal antibodies. TS, NK and KP conceived and designed the experiments. SS, TS, NK and KP interpreted the data and prepared the manuscript. All authors read and approved the manuscript.

\section{Competing interests}

The authors declare that they have no competing interests.

Received: 11 August 2010 Accepted: 26 November 2010

Published: 26 November 2010

\section{References}

1. World Health Organization: Screening donated blood for transmission transmissible infections: recommendations. 2009 [http://www.who.int/ bloodsafety/ScreeningTTI.pdf], (accessed 6th August 2010).

2. Siitari H: Dual-label time-resolved fluoroimmunoassay for the simultaneous detection of adenovirus and rotavirus in faeces. $J$ Virol Methods 1990, 28:179-188.

3. Meriö L, Pettersson K, Lövgren T: Monoclonal antibody-based dual-label time-resolved fluorometric assays in a simplified one-step format. Clin Chem 1996, 42:1513-1517.

4. Eriksson $S$, Vehniäinen $M$, Jansén $T$, Meretoja V, Saviranta P, Pettersson $K$, Lövgren T: Dual-label time-resolved immunofluorometric assay of free and total prostate-specific antigen based on recombinant $\mathrm{Fab}$ fragments. Clin Chem 2000, 46:658-666.

5. Ankelo M, Westerlund A, Blomberg K, Knip M, llonen J, Hinkkanen AE: Time-resolved immunofluorometric dual-label assay for simultaneous detection of autoantibodies to GAD65 and IA-2 in children with type I diabetes. Clin Chem 2007, 53:472-479. 
6. Vaidya $H C$, Beatty BG: Eliminating interference from heterophilic antibodies in a two-site immunoassay for creatine kinase MB by using $F$ $\left(a^{\prime}\right)_{2}$ conjugate and polyclonal IgG. Clin Chem 1992, 38:1737-1742.

7. Väisänen V, Peltola, Lilja H, Nurmi M, Pettersson K: Intact free prostatespecific antigen and free and total human glandular kallikrein 2 . Elimination of assay interference by enzymatic digestion of antibodies to $\mathrm{F}\left(\mathrm{ab}{ }^{\prime}\right)_{2}$ fragments. Anal Chem 2006, 78:7809-7815.

8. Härmä H, Soukka T, Lövgren T: Europium nanoparticles and time-resolved fluorescence for ultrasensitive detection of prostate-specific antigen. Clin Chem 2001, 47:561-568.

9. Huhtinen P, Soukka T, Lövgren T, Härmä H: Immunoassay of total prostate-specific antigen using europium(III) nanoparticle labels and streptavidin-biotin technology. J Immunol Methods 2004, 294:111-122.

10. Valanne A, Huopalahti S, Vainionpää R, Lövgren T, Härmä H: Rapid and sensitive $\mathrm{HBsAg}$ immunoassay based on fluorescent nanoparticle labels and time-resolved detection. J Virol Methods 2005, 129:83-90.

doi:10.1186/1477-3155-8-27

Cite this article as: Myyryläinen et al: Simultaneous detection of Human Immunodeficiency Virus 1 and Hepatitis B virus infections using a duallabel time-resolved fluorometric assay. Journal of Nanobiotechnology 2010 8:27.

\section{Submit your next manuscript to BioMed Central} and take full advantage of:

- Convenient online submission

- Thorough peer review

- No space constraints or color figure charges

- Immediate publication on acceptance

- Inclusion in PubMed, CAS, Scopus and Google Scholar

- Research which is freely available for redistribution

Submit your manuscript at www.biomedcentral.com/submit
C Biomed Central 